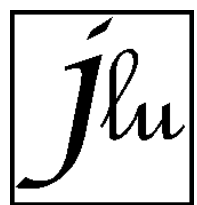

Jurnal Luminous:

Riset IImiah Pendidikan Fisika

Vol. 1 No. 1 (2020) 20-26
E-ISSN 2715-6990

P-ISSN 2715-9582

Januari 2020

https://jurnal.univpgri-

palembang.ac.id/index.php/luminous

\title{
PENGARUH MEDIA LECTORA INSPIRE TERHADAP KEMAMPUAN BERPIKIR KRITIS SISWA PADA MATERI DIFRAKSI DAN INTERFERENSI GELOMBANG MEKANIK KELAS XI SMA
}

\author{
${ }^{1}$ Lutfiana Dewi, ${ }^{2}$ Susilawati, ${ }^{3}$ Wawan Kurniawan \\ 1,2,3 Prodi Pendidikan Fisika, FKIP, Universitas PGRI Semarang \\ ${ }^{2}$ susilawati@upgris.ac.id, ${ }^{2}$ susilawati.physics@gmail.com
}

\begin{abstract}
Abstrak
Penelitian ini bertujuan untuk mengetahui pengaruh media Lectora Inspire untuk meningkatkan kemampuan berpikir kritis pada pembelajaran Difraksi dan Interferensi Gelombang Mekanik kelas XI program MIPA di SMA N 1 Kayen. Penelitian ini menggunakan quasi eksperimen pre-test post-test control group design. Populasi penelitian ini adalah seluruh siswa kelas XI MIPA SMA N 1 Kayen. Sampel penelitian dipilih secara acak. Didapatkan kelas XI MIPA 1 sebagai kelas kontrol dan XI MIPA 5 sebagai kelas eksperimen. Teknik pengumpulan data berupa teknik dokumentasi data, metode tes dan angket. Berdasarkan hasil penelitian dapat disimpulkan bahwa terdapat pengaruh media Lectora Inspire terhadap kemampuan berpikir kritis siswa pada materi Difraksi dan Interfrensi Gelombang Mekanik Kelas XI SMA N 1 Kayen Tahun Pelajaran 2018/2019.
\end{abstract}

Kata kunci : media lectora inspire, berpikir kritis, difraksi dan interferensi

(C) 2020 Pendidikan Fisika FKIP UPGRI Palembang

\section{PENDAHULUAN}

Fisika merupakan salah satu cabang ilmu pengetahuan alam atau IPA. Menurut kamus besar bahasa Indonesia "fisika" adalah suatu ilmu yang mengenai zat serta energi. Selain itu, fisika merupakan ilmu pengetahuan yang mempelajari sifat serta gejala pada benda benda alam. Tujuan pembelajaran fisika adalah mengembangkan kemampuan berpikir. Kemampuan berpikir merupakan dasar dalam suatu proses pembelajaran (Heong et all, 2011). Berpikir kritis memungkinkan siswa untuk menganalisis pikirannya dalam menentukan pilihan dan menarik kesimpulan dengan cerdas. Kemampuan berpikir kritis merupakan bagian dari kemampuan berpikir tingkat tinggi (Heong et all, 2011).

Kemampuan berpikir kritis merupakan suatu hal yang penting untuk dilakukan dan perlu dilatihkan pada siswa mulai dari jenjang pendidikan dasar sampai jenjang pendidikan menengah. Kemampuan berpikir kritis merupakan kompetensi yang harus dimiliki oleh siswa. Kemampuan berpikir, baik berpikir kritis maupun berpikir kreatif merupakan kemampuan yang penting untuk dimiliki siswa agar siswa dapat memecahkan persoalanpersoalan(Perdani et all, 2014). Kemampuan berpikir kritis merupakan kemampuan yang rasional dan reflektif yang terfokus pada 
memutuskan apa yang harus dipercaya atau dilakukan (Ennis, 2011).

Permasalahan dalam proses belajar mengajar kurang mendorong pada pencapaian kemampuan berpikir kritis (Sanjaya, 2014). Kenyataan di lapangan tentang kelas VIII A SMP Negeri 2 Gajah Demak setiap kali berlangsung proses belajar mengajar jumlah siswa yang aktif kurang lebih 13anak dari 20 anak atau jikalau diprosentase ada $65 \%$. Belum maksimalnya prosentase siswa yang aktif dalam proses belajar mengajar ini berdampak pula terhadap kurang maksimalnya hasil elajar IPA Fisika(Riyanti \&Wawan Kurniawan, 2009). Hal tersebut juga terjadi pada proses pembelajaran fisika di dalam kelas, dimana pada proses pembelajaran diarahkan kepada kemampuan siswa untuk menghapal informasi belum mengarahkan siswa pada kemampuan berpikir kritis. Selain itu, pembelajaran yang masih menggunakan metode tradisional (Gok \& Silay, 2008).

Berdasarkan hasil observasi awal di SMA 1 Bae Kudus ditemukan beberapa kendala pada proses pembelajaran. Pertama pembelajaran fisika banyak mengandung prinsip, konsep, dan teori yang abstrak sulit dipahami oleh siswa. Kedua siswa kurang optimal saat mengikuti pembelajaran sehingga pemahaman konsep siswa kurang baik dan berakibat siswa hanya menghafal materi.

Banyak faktor yang mempengaruhi hal tersebut salah satunya adalah pemanfaatan media pembelajaran yang kurang menarik dan inovatif. Penggunaan media pendidikan secara tepat dan bervariasi dapat mengatasi sikap pasif anak didik(Sadiman, 2011). Proses pembelajaran seperti ini menuntut agar dalam kegiatan belajar mengajar siswa tidak lagi berperan pasif hanya mendengarkan penjelasan guru dan mencatat hal-hal yang dianggap penting(Susilawati, 2015). Salah satu alternatif pembelajaran yang dapat diterapkan untuk meningkatkan berpikir kritis adalah dengan memanfaatkan media pelajaran yang menarik dan inovatif. Media berasal dari bahasa latin yaitu medius yang secara harfiah berarti tengah, perantara atau pengantar (Arsyad, 2007). Bahwa pembelajaran merupakan suatu sistem, yang terdiri dari berbagai komponen yang saling berhubungan satu dengan yang lain. di mana lingkungan seseorang secara sengaja dikelola untuk memungkinkan ia turut serta dalam tingkah laku (Rusman, 2017). Media yang digunakan dalam penelitian media lectora inspire. Lectora digunakan untuk membuat kursus online pelatihan, penilaian, dan presentasi. Konten dikembangkan dengan authoring software Lectora dapat dipublikasikan untuk berbagai output seperti HTML, Single File executable, dan CD-ROM. Yang mana pada lectora inspire ini memiliki fitur yang cukup lengkap mulai dari menyisipkan video, gambar sampai menyisipkan game pun bisa. Lectora adalah Authoring tool untuk pengembangan konten e-learning yang dikembangkan oleh Trivantis Corporation (Mas'ud, 2012) Lectora mampu membuat kursus online cepat dan sederhana". Hal ini tentu sangat membantu kinerja guru dalam memaksimalkan proses pembelajaran.

Dari latar belakang di atas upaya yang dapat dilakukan dalam pembelajaran yaitu dengan mengetahui pengaruh kemampuan 
berpikir kritis siswa ketika proses pengajarannya mengunakan aplikasi lectora inspire. Penelitian mengenai pengaruh media pembelajaran sebelumnya dilakukan oleh (Kurniawan, 2015) Pengembangan Media Pembelajaran Mengguakan Software Lectora Inspire untuk Meningkatkan Motivasi Belajar Fisika Siswa Kelas X. Hasil dari penelitian menunjukkan adanya peningkatan motivasi belajar siswa ketika diterapkan dengan multimedia lectora dibandingkan pembelajaran tanpa menggunakan media pembelajaran. Dari penelitian tersebut peneliti ingin melakukan penelitian dengan menggunakan media Lectora Inspire tetapiuntuk mengukur kemampuan berpikir kritis siswa dengan materi difraksi dan interferensi gelombang mekanik. Peneliti memilih materi difraksi dan interferensi gelombang mekanik ada beberapa konsep yang abstrak yang sulit dipahami oleh siswa jika tidak melihat fenome secara langsung atau tidak melalui praktikum.

\section{METODE}

Metode yang diguakan adalah Quasi Experimental Design. Quasieksperimen merupakan desain penelitian yang mempunyai kelompok kontrol tetapi tidak dapat berfungsi sepenuhnya untuk mengontrol variabel variabel luar yang mempengaruhi pelaksanaan eksperimen(Sugiyono, 2012).Desain penelitian yang digunakan dalam penelitian ini adalah Pretest -Posttest Control Group Design dengan dua kelompok yang masing-masing dipilih secara random/acak (R). Kelompok pertama diberi perlakuan $(X)$ dan kelompok yang lain tidak (Sugiyono, 2012).

\section{HASIL DAN PEMBAHASAN}

Penelitian ini bertujuan untuk mengetahui ada atau tidaknya pengaruh pembelajaran berbantuan media lectora inspire terhadap kemampuan berpikir kritis siswa kelas XI SMA N 1 Kayen tahun ajaran 2018/2019. Media yang digunakan dalam penelitian ini yaitu Lectora Inspire pada materi difraksi dan interferensi gelombang mekanik. Instrumen yang digunakan dalam penelitian ini berupa tes dan angket. Lembar tes berisi 10 soal uraian yang sebelumnya berjumlah 15 soal saat di lakukan ujicoba. Sebelum diujicobakan instrumen diujikan terlebih dahulu ke dosen ahli ada beberapa aspek yang ditelaah yaitu Materi, konstruk, dan bahasa dapat ditarik kesimpulan bahwa hasilnya persentasenya $90 \%-100 \%$ jadi intrumen tes dan angket layak untuk digunakan. Hasil dari ujicoba soal berasal dari analisis validitas, reliabilitas, taraf kesukaran dan daya pembeda yang rata - rata. Pada tahap validasi dimana ada 4 buah soal yang tidak valid. Sedangkan pada tahap reliabilitas didapatkan nilai $r_{\text {hitung }}=0,969$ lebih besar dari $r_{\text {tabel }}=0,344$ maka soal dikatakan reliabel. Serta untuk taraf kesuraka didapatkan hasil yang beragam yaitu ada yang mudah, sukar dan sulit dan juga daya pembeda yang berbeda-beda pula. Sehingga menghasilkan nilai baik pada soal uraian bernomor 1, 2, 3,7,8, 9, 11,13, 14, 15. untuk siap digunakan sebagai soal pretest dan posttest. Soal yang digunakan sudah sesuai dengan indikator kemampuan berpikir kritis. 
Data yang diperoleh dari hasil penelitian ini menunjukkan adanya pengaruh perlakuan yang diberikan pada kelas sampel. Ada dua kelas sampel yaitu kelas kontrol dan kelas eksperimen. kelas XI MIPA 1 sebagai kelas kontrol dan kelas XI MIPA 5 sebagai kelas eksperimen. Terlebih dahulu peneliti melakukan analisis tahap awal yaitu menguji normalitas dan homogenitas untuk mengetahui keadaan awal apakah sampel berdistribusi normal dan homogen atau tidak. Data yang diperlukan untuk uji normalitas dan homogenitas adalah nilai pretest siswa. Dari pengujian normalitas menggunakanStatistical Product and Service Solutions (SPSS) dimana didapatkan hasil nilai signifikansi pada kelas eksperimen yaitu 0, 068 sedangkan pada kelas kontrol 0,058 >0,05, artinya sampel kedua kelas tersebut berasal dari data yang berdistribusi normal, maka kedua sampel tersebut berdistribusi normal. Sedangkan pengujian homogenitas diperoleh hasil dimana nilai signifikansi 0,062>0,05 maka dapat dikatakan bahwa kedua sampel dalam kondisi homogen sebelum dilakukan penelitian. Artinya, kedua kelas memiliki kemampuan yang sama. Sampel yang akan digunakan dalam penelitian ini yaitu XI MIPA 5 sebagai kelas eksperimen dan XI MIPA 1 sebagai kelas kontrol.

Penelitian ini terdapat dua hipotesis yaitu adanya pengaruh media lectora inspire terhadap kemampuan berpikir kritis siswa pada materi difraksi dan interferensi gelombang mekanik yang disebut $\mathrm{H}_{\mathrm{a}}$ dan tidak ada pengaruh media lectora inspire terhadap kemampuan berpikir kritis siswa pada materi difraksi dan interferensi gelombang mekanik yang disebut $\mathrm{H}_{0}$. Untuk mengetahui apakah hipotesis tersebut diterima atau ditolak maka dilakukan uji yaitu dengan menggunakan uji $t$ didapatkan hasil bahwa thitung $>$ ttabel dengan nilai thitung $=4,11$ dan ttabel $=1,99$ sehingga dapat diketahui Ha diterima dan Ho ditolak.

Untuk memperkuat adanya pengaruh perlakuan pada kelas sampel dilakukan uji gain yang bertujuan untuk mengetahui peningkatan keterampilan berpikir kritis siswa. Didapatkan hasil pada kelas eksperimen dengan taraf 0,55 dengan kategori sedang. Sedangkan pada kelas kontrol dengan taraf 0,35 kategori sedang. Dimana keterampilan berpikir siswa pada kelas eksperimen yang menggunakan media lectora inspire lebih baik daripada kelas kontrol dengan pembelajaran konvensional menggunkan buku sumber paket fisika.Untuk Persentase tiap indikator pada kelas ksperimen dapat dilihat pada Grafik dibawah ini.

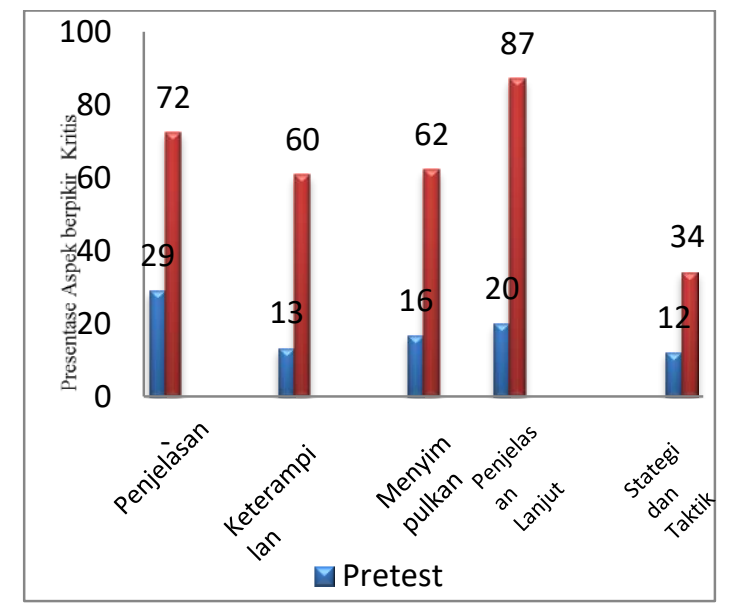

Gambar 1 Grafik Persentase Aspek Berpikir Kritis Kelas Eksperimen

Grafik diatas menunjukkan bahwa kemampuan berpikir kritis kelas eksperimen mengalami peningkatan yang cukup tinggi. Terlihat jelas pada hasil persentase sebelum 
diberikan perlakuan dan sesudah diberikan perlakuan. Kelima aspek berpikir kritis mengalami peningkatan yang signifikan. Inidikator paling tinggi dicapai yaitupenjelasan lanjut mencapai 87\%, Sedangkan pada aspek indikator strategi dan teknik kenaikannya masih lebih rendah yaitu jika dibandingkan dengan ke empat aspek indikator yang lain yaitu hanya 34\%. Hasil pembelajaran pada kelas eksperimen memperlihatkan bahwa siswa kelas eksperimen memperhatikan pembelajaran didalam kelas yang dilakukan dengan berbantuan media lectora inspire. Pada indikator penjelasan lanjut diperoleh persentase paling tinggi karena pada saat proses pembelajaran peneliti sering bertanya suatu fenomena yang ada di media lectora inspire kepada siswa. Para siswa bersemangat dan berantusias menjawab pertanyaan dari peniliti, selain itu juga kalau peneliti menyuruh siswa untuk mengerjakan soal siswa terlihat dengan bersungguh - sungguh mengerjakan soal dan mengerjakanya didepan kelas. Siswa terlihat fokus dan konsentrasi mengamati animasi materi difraksi dan interferensi yangada di media lectora inspire.Untuk Persentase tiap indikator pada kelas ksperimen dapat dilihat pada Grafik dibawah ini.

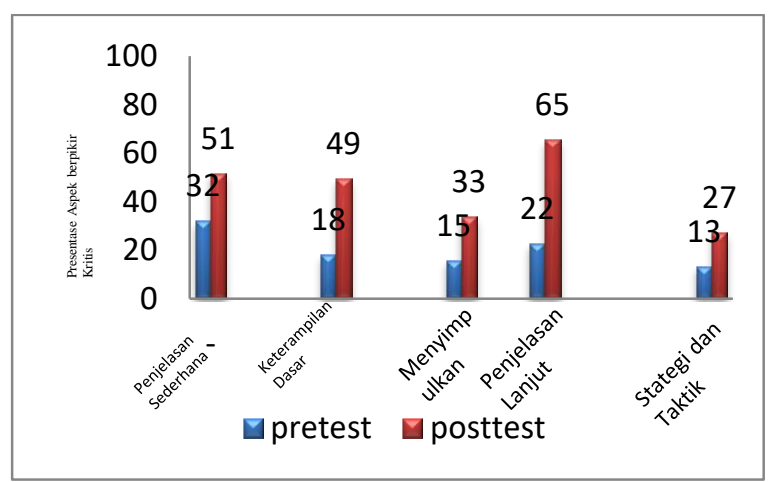

Gambar 2 Grafik Persentase Aspek Berpikir Kritis Kelas Kontrol
Melalui perhitungan uji-t yang telah dilakukan, ternyata perbedaan itu sangat signifikan, artinya perbedaan dikarenakan perlakukan dengan berbantuan media lectora inspire. Pembelajaran fisika dengan media lectora inspire memberikan kesempatan bagi siswa untuk meningkatan prestasi belajar dan mengembangkan kemampuan berpikir kritis siswa. Hal ini memungkin siswa untuk lebih mudah menerima dan memahami materi yang disampaikan oleh guru, sehingga siswa dapat memunculkan minat berpikir kritis.

Hasil penilaian angket respon siswa terhadap proses pembelajaran berbasis media Lectora Inspire.

Tabel 1. Penilaian angket respon siswa

\begin{tabular}{|c|l|c|}
\hline No. & \multicolumn{1}{|c|}{ Aspek yang Ditanyakan } & Persentase \\
\hline 1. & $\begin{array}{l}\text { Pembelajaran Difraksi dan } \\
\text { interferensi berbasis Media } \\
\text { Lectora Inspire }\end{array}$ & $87 \%$ \\
\hline 2. & Memfokuskan Pertanyaan & $76 \%$ \\
\hline 3. & $\begin{array}{l}\text { Mempertimbangkan } \\
\text { kredibilitas (kriteria) } \\
\text { suatusumber. }\end{array}$ & $80 \%$ \\
\hline 4. & $\begin{array}{l}\text { Mendeduksi dan } \\
\text { mempertimbangkan deduksi }\end{array}$ & $79,5 \%$ \\
\hline 5. & $\begin{array}{l}\text { Mendefinisikan istilah dan } \\
\text { mempertimbangkan suatu } \\
\text { definisi. }\end{array}$ & $76,6 \%$ \\
\hline 6. & Memutuskan suatu tindakan. \\
\hline
\end{tabular}

Didapatkan hasil siswa merasa senang mempelajari materi tentang difraksi dan interferensi gelombang mekanik menggunakan media Lectora Inspire. Sedangkan butir pernyataan indikator kemampuan berpikir kritis 
yang ada pada angket mendapatkan hasil diatas $50 \%$ bisa dikatakan bahwa kemampuan berpikir kritis siswa baik dan mengalami peningkatan. Kemampuan berpikir kritis siswa dapat meningkat cukup signifikan melalui model pembelajaran CLIS Children Learning in Science berbantuan LKS materi Elastisitas dan Hukum Hooke (Renjani, Susilawati \& Khoiri). Siswa dapat mendeskripsikan dan mempresentasikan gambar, tulisan, grafik, simbol dan hubungan melalui bantuan media pembelajaran (Susilawati, Et al., 2018).

\section{SIMPULAN}

Berdasarkan hasil penelitian yang telah dilaksanakan dapat disimpulkan bahwa:

1. Terdapat pengaruh yang signifikan dengan menggunakan pembelajaran berbantuan media lectora inspire pada materi difraksi dan interferensi gelombang mekanik terhadap kemampuan berpikir kritis siswa kelas XI SMA N 1 Kayen melalui perhitungan uji t pihak kanan didapat kan $t$ hitung $>t$ tabel dengan nilai $t$ hitung $=4,11$ dan $\mathrm{t}$ tabel $=1,99$.

2. Peningkatan kemampuan berpikir kritis pada kelas eksperimen lebih baik dari pada kelas kontrol. Hal ini juga dibuktikan dari hasil gain <g>pada kelas eksperimen sebesar 0,55 dalam kategori sedang dan kelas control sebesar 0,35 dalam kategori sedang. Dilihat dari hasil rekap, maka kelas eksperimen memiliki hasil yang lebih baik.

\section{DAFTAR PUSTAKA}

Arsyad, Azhar . 2007. Media Pembelajaran. Jakarta: PT. Raja Grafindo Persad.

Ennis, R. H. 2011. The Nature of Critical Thinking: An Outline of Critical Thinking Dispositionsand Abilitiesi.Emeritus Professor, University of IllinoisLast Revised.

Fisher, Alec. 2009. Berpikir Kritis Sebuah Pengantar. Surabaya: Erlangga.

Gok, T.\& Silay, I. 2008. Effect problem Solving Strategy Teaching on the ProblemSolving Atitude of CooperatingLearning groupin Physics educatiuon. Juornal of Theory and practice in Education, 4(2):253-266.

Heong, Y.M., Othman, W.D., Md Yunos, J., Kiong, T.T., Hassan, R., \& Mohamad, M.M. 2011. The Level of Marzano Higher Order Thinking Skills Among Technical Education Students. International Journal of Social and Humanity, Vol. 1, No. 2: 121125.

Kurniawan, A.2016. Pengembangan Media Pembelajaran Menggunakan Software Lectora Inspire Untuk Meningkatkan Motivasi Belajar FisikaSiswa . Universitas Muhammadiyah Purworejo. 99.

Mas'ud, Muhamad. 2012. Tutorial Lectora 1 Membuat Multimedia Pembelajaran dengan Lectora. Yogyakarta: Pustaka Shonif.

Perdani, W., Santoso, S \& Ramli, M. 2014. Peningkatan Kemampuan Berpikir Kritis dengan Model Inkuiri pada Materi Sistem 
Indera Kelas XI MIA 6 SMA N 4 Surakata Tahun Pelajaran 2014/2015.SP-005-5.

Renjani, MKD., Susilawati \& Khoiri, N. 2018. Deskripsi Kemampuan Berpikir Kritis Siswa SMA melalui Model Pembelajaran CLIS (Children Learning in Science) Berbantuan LKS pada Materi Elastisitas dan Hukum Hooke. Jurnal Penelitian Pembelajaran Fisika, 9 (1): 21-27

Riyanti, da Wawan Kurniawan. 2009. Peningkatan Hasil Belajar Ipa-Fisika Melalui Permainan Monopoli Bagi Siswa Kelas Viii A Smp Negeri 2 Gajah Demak Semester Genap Tahun Pelajaran 2008/2009. JP2F, Volume 1 Nomor 1 April 2010

Rusman, 2017. Belajar dan Pembelajaran Berorientasi standar proses pendidikan. Jakarta: Kenacana.
Sanjaya, W. 2014. Strategi Pembelajaran Berorientasi Standar Proses Pendidikan . Jakarta: Prenadamedia Group.

Sadiman, arif S. Dkk. 2011. Media Pendidikan. Jakarta: Rajawali pers.

Sugiyono. 2012. Metode Penelitian Kuantitatif Kualitatif dan R\&D. Bandung: Alfabeta.

Susilawati, Wijayanto, Khoiri, N., Masturi \& Xaphakdy. 2018. Learning Experience of Pre-service Physics Teachers in Developing Simple Project Loaded by Life Skills. Jurnal Pendidikan IPA Indonesia, 7 (1): $122-129$

Susilawati, dan Nyoman Sridana. 2015. Pengaruh Model Pembelajaran Inkuiri Terbimbing Terhadap Keterampilan Proses Sains Siswa. Jurnal Tadris IPA Biologi FITK IAIN Mataram. Volume VIII, Nomor 1. 